\title{
Regional Policies in Post-Mao China
}

\author{
KJELD A. LARSEN
}

Regional policy is part of development strategy in general. Since 1978 two development strategies are complementing and competing with each other in China, readjustment and reform, but both incorporate and react against elements of the legacy of past strategies, the Soviet and the Maoist. ${ }^{1}$

In a regional perspective the most central theme for reformers has been to find new ways to avoid the classical conflict, inherent in former strategies, between branches (tiao tiao) and areas (kuai kuai): centralized or vertical planning, via central bureaus and ministries, according to the branch principle; and decentralized or horizontal planning, especially at the provincial level, according to the committee or area principle. ${ }^{2}$

The concept development strategy can be defined as a correlated understanding of aims and means for economic and social development. This paper will concentrate on economic development. Aims in regard to regional policy in the era of reform will be the first aspect to be outlined. The financial and investment policy of the state as the most central means in regional policy will be discussed next. At the end the results of regional policy will be discussed: to what extent has a deepening or equalizing of existing regional differences taken place in relation to development strategy practised? Production, agricultural and industrial, in the 29 provincial units in the period of 1949-87 will make up the statistical basis for this evaluation. For reasons of space provinces in this paper have been aggregated to greater regions, containing provinces with similar level of development.

\section{The Regional Policy of Reform Strategy}

In the opinion of reformers a new regional economic structure has to be set up, the main principle of which is based on specialization and division of labour. A central article in the discussion of the new regional economic structure is that of Chen Jiyuan. ${ }^{3}$ 
Chen Jiyuan sums up the criticism of the former regional policy in terms of two main problems of regional economic structure: insufficient attention to the exploitation and development of coastal industry, and the arbitrary uniformity of the previously practised development strategy, irrespective of local variation. According to Chen the basic guidelines for the creation of a regional economic structure are "developing the advantages and avoiding shortcomings and developing superiority.« Economic superiority includes both the natural basis as well as the productive forces developed through history.

As for the planning of regions for industrial production Chen stresses that a more equal distribution of industry is a rather long-term goal, but that the course of history shows that regional development in any country always progresses from imbalance to balance, and then from balance to imbalance. This dialectic process is exemplified by the regional development in the USA.

Chen concludes by saying that national economic structure must be based on regional economic structure: A relative complete and indepen dent industrial system and a national economic system must thus be established, but not at every regional level. Specializing on a comparative basis each region must build up a relatively complete economic system, but it must not aim for a uniform, coordinated development of agriculture, light industry and heavy industry.

\section{Key Cities and Economic Zones}

In a new organizational structure the cities are intended to play a central role as economic centres that will promote economic links within and between regions. Ma Hong, one of the important reform economists, deals with the establishment and future role of economic centres. ${ }^{4}$ The economic centre based on a city of a certain size is the expression of a certain phase in the development of the commodity economy; and the modern economic centre is the result of capitalist commodity production. According to Ma Hong the function of the Chinese cities as economic centres should be revived, but within the context of a socialist commodity economy. Ma Hong's vision is that the economic centres based on key (or core) cities should be linked with other key cities and neighbouring economic regions so that an organic whole is formed as a network for nationwide economic activities. A central task for economic centres in forming this 
network will be to help to break down the barriers resulting from the chanelling of administrative control through branches and areas.

A central task for the reformers has been to create important interest groups in support of their strategy of more independence to the enterprises. The most natural allies to rely upon for the reform politicians and economists are exactly the major cities.

As the most important local area administrations, the key cities are supposed to have the potential to break down branch and provincial power and create economic networks that transcend the provincial boundaries. The idea is to transfer large urban plants from central and provincial level to key city administrations.

One way of removing the branch demarcation lines and organizing coordination and cooperation across former boundaries is to extend city boundaries and gradually form economic zones or networks that cut across regions. As part of the effort to turn key cities into economic zones since 1983 nine cities have achieved an economic status corresponding to that of the provinces. These nine cities are Chongqing, Wuhan, Shenyang, Dalian, Guangzhou, Harbin, Xian, Qingdao and Ningbo.

In parallel the administrative map has been redrawn in two provinces, first Liaoning, then Jiangsu: the prefecture level has been abolished, and the counties of the former prefecture have been brought into the economic orbit of the prefecture level city.

A number of articles by economists and geographers in the 1980s are concerned with the regional unit which is to replace the administrative region for economic purposes - the economic zone. ${ }^{5}$

The economic zone is a comprehensive production system whose backbone is specialized production sectors of national importance. On the basis of specialization the economic zone is to establish inter-regional contacts with all other economic zones in the nation, and must therefore not be a closed system. The integration points of the economic zones are the key cities.

It is hard to know how many economic zones at the national level in reality have been formed, and to what extent they are functioning.

The Shanghai economic zone has been established in 1982 in order to create an export-oriented economic zone for industrial processing. In 1985 it was expanded, so that it now covers the following provincial units: Shanghai, Jiangsu, Zhejiang, Anhui and Jiangxi, with Shanghai as the most important key city. 
The Shanxi energy base is to be developed into a regional energy, heavyindustry and chemical-industry base taking the region's extensive coal reserves as its point of departure. The zone includes Shanxi, one prefecture in Inner Mongolia, northern Shaanxi and western Henan.

The North Eastern Economic zone was established in 1985 with the object of coordinating the development of China's most important heavyindustry base. The zone covers the three northeastern provinces Heilongjiang, Jilin and Liaoning along with three prefectures and one city in the adjacent coal-rich parts of Inner Mongolia.

\section{The Greater Regions for Regional Specialization}

Both the Sixth Five-Year Plan, adopted in December $1982^{6}$ and the Seventh Five-Year Plan, adopted in April $1986^{7}$ contain chapters on the policy for regional economic development. Both plans divide China into three economic greater regions, and outlines their place in the national division of labour.

It is interesting that the provincial composition of the three greater regions differs to some extent from the Sixth to the Seventh plan. The east coast region of the two plans (11 provincial units) coincides exactly with each other; in the Seventh Five-Year Plan the central region consists of nine provincial units: Shanxi and Inner Mongolia in the North, Jilin and Heilongjiang in the North East, Anhui and Jiangxi in the East, and Henan, Hubei and Hunan in the Central-Southern region; while the western region consists of the nine provincial units in the two backward regions of the South West (Sichuan, Guizhou, Yunnan, Tibet) and North West (Shaanxi, Gansu, Ningxia, Qinghai and Xinjiang).

The principles for regional economic development in the two plan documents are the same: the wave of development is to flow from east to west.

In the developed east coast region the emphasis is to be on know-how and technology-intensive industry and the manufacture, backed by foreign capital, of high-quality consumer goods, including goods for the overseas market. The aim is two-fold: partly to gain access to the world market, partly to contribute technology to the development of China's interior.

In order to attract foreign capital and advanced technology the Central Government in 1979 established four special economic zones in the Guangdong and Fujian provinces. In 1984 China opened 14 coastal cities 
for foreign investment. Finally, in 1988 the open economic coast zones were extended to cover an area with 160 million people. It was also decided to separate Hainan island from Guangdong as a new province and make it the fifth special economic zone in the country.

In the central region the emphasis is to be on the development of energy resources (electricity, coal and oil) and on the production of steel, non-ferrous metals, chemicals and building materials, i.e. industries supplying raw materials and semi-manufactures, also for the support of the economic development of the coastal region. The necessary capital and technology is supposed partly to come from economic and technological cooperation with the east coast provinces.

Finally, in the poorly developed Western region the emphasis will be on the development of agriculture, forestry, cattle-breeding, transport, energy and mineral resources, as well as the processing industries, thus creating a basis for future development. The aim of production is partly a higher degree of self-sufficiency, e.g. in regards to grain and consumer goods, and partly a better contribution to national division of work.

\section{Redistribution via the State Budget}

The state or national budget in China comprises not only the revenues and expenditures of the central government, but also revenues and expenditures of the provincial units.

The sources of state revenues are mainly the incomes of state industrial enterprises, primarily their profits, and taxes levied on industrial and commercial enterprises. Since 1979 there has been a gradual reorganisation from profit transfer to taxation of state enterprises, a process which was almost completed in 1985. This change is considered by the reformers as a step to spur the initiative and independence of the enterprises, but also to increase revenues to the central government.

There are, however, several financial sources that are not included in the state budget - the socalled extra-budgetary funds. These funds consists partly of revenues flowing to state enterprises and departments administrating them, partly of revenues flowing to non-profit administrative units and finally revenues due to provincial and other local governments.

The proportion of extra-budgetary funds to state budget revenues have risen from $8.5 \%$ in 1957 , to $15-21 \%$ in the period $1958-1970$ and then, gradually, to a high figure of $92.4 \%$ in $1988 .{ }^{8}$ One serious consequence of this 
decentralization of financial power has been increasing local investment activity, which has posed problems for the central government in its efforts to create balance in the economy.

Table 1.Distribution of State Budgetary Expenditures Between Central Government and Local Governments, 1950-56 and Plan 1989, in percent.

\begin{tabular}{lcccc} 
Category & \multicolumn{2}{c}{ Central } & \multicolumn{2}{c}{ Local } \\
\hline & $1950-56^{1}$ & $1989^{2}$ & $1950-56^{1}$ & $1989^{2}$ \\
Economic Construction & 83.8 & 72.0 & 16.22 & 8.0 \\
Culture, Education and Health & 28.2 & 12.9 & 71.8 & 87.1 \\
National Defence & 100.0 & 99.1 & 0.0 & 0.9 \\
Administration & 20.1 & 9.6 & 79.9 & 90.4 \\
Credits and Loan Repayments & 100.0 & 100.0 & 0.0 & 0.0 \\
Other & 76.7 & 36.8 & 23.3 & 63.2 \\
\hline
\end{tabular}

${ }^{1}$ Nicholas R. Lardy, Economic Growth and Distribution in China (Cambridge, Mass.: Cambridge University Press, 1978), p. 71.

${ }^{2}$ Calculations based on Wang Bingqian, "Report on the Implementation of the State Budget for 1988 and the Draft State Budget for 1989« Beijing Review, 1989, No. 18, pp. XIV-XV.

The distribution of state budgetary expenditures between the central and the local governments has been published for the first half of the 1950s and plan figures for 1989 (see Table 1). The principle guiding the distribution of expenditures between the central and local governments is that activities are normally administrated and financed at the same level. Social (health, education and culture) and administrative expenditures are thus primarily a local matter; national defence and credits and loan repayments are exclusively central concern; while the costs of economic construction (capital construction and technological transformation) in the 1950s were primarily a central matter. In connection with the regional decentralization in 1958 and 1970-71 and with the rapid growth of extra-budgetary funds since 1970, there has been a shift toward local financing of economic construction costs. Investment from the state budget, which made up about $90 \%$ of national investment in capital construction during the First FiveYear Plan 1953-57, constitutes less than 40\% during the Seventh Five-Year Plan 1986-90.

One aim of the unitary state budget is to contribute to the adjustment of relationship between rich and poor provincial units: revenues are transferred from developed to backward provincial units in the form of state subsidies. The state budget, in monetary terms, arranges for the capital 
necessary for the implementation of the state plan. Thus the outflow of materials from provinces that are net suppliers of materials to other provinces can be measured in terms of the flow of revenues transferred to the central government, while the value of the budget subsidies received by a province gives a measure of the net inflow of materials.

Table 2. Central and Local (Provincial) Government Shares of Budgetary Revenues and Expenditures, in percent.

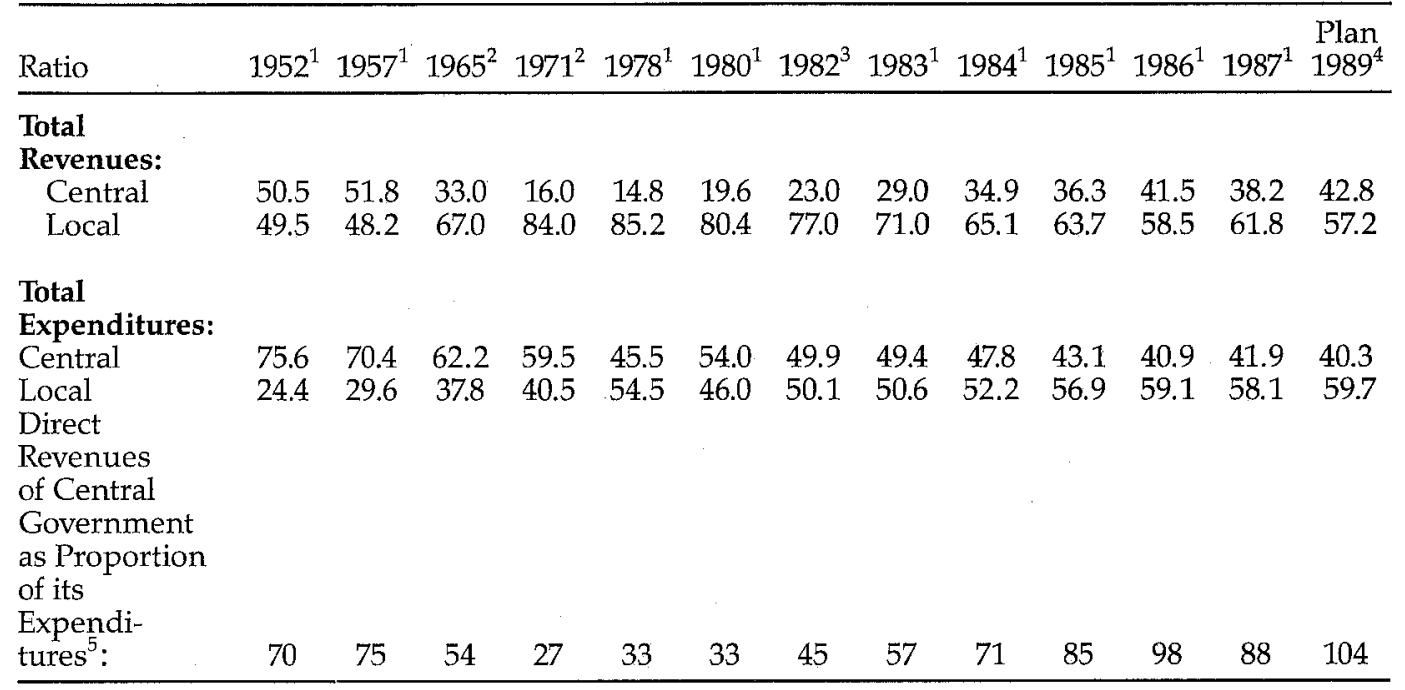

Figures based on calculations from provincial budgets.

World Bank, China - Socialist Economic Development Vol.1, (Washington D.C., 1983) Table 4.3, p. 348 and Table 4.9 , p. 355.

Figures based on calculations in China Statistical Yearbook (Beijing, 1988) p. 681.

Figures based on calculations in Wang Bingqian, "Report on the Implementation of the State Budget for 1988 and on the Draft Budget for 1989«, Beijing Review, 1989, No. 18, pp. XIV-XV.

5 Calculated from central revenues and expenditures.

Table 2 gives a review of central government and provincial shares of the revenues and expenditures in the state budget. As a result of increasing decentralization to the provincial level since 1957 there was a gradual reduction in the percentage of budgetary revenues gathered directly by the central government from $51.8 \%$ in 1957 to $14.8 \%$ in 1978 , but since then there has been a gradual increase in the central government's percentage, which had risen to $38.2 \%$ in 1987 and is planned to increase to $42.8 \%$ in 1989 . Similarly, there was a drop in the share of state budget expenditure allocated by the central government from $70.4 \%$ in 1957 to $45.5 \%$ in 1978 . After a small rise, peaking in 1980 at $54.0 \%$, the central government percentage gradually fell to $41.9 \%$ in 1987 and is expected to fall to $40.3 \%$ in 1989 . 
As a consequence of the relatively more rapid drop in the central government share of revenues collected than in its share of allocated expenditure in the 1957-71 period, the central government had a decreasing ability to finance its expenditures from directly collected revenues. The directly collected revenues of the central government as a percentage of its expenditures thus fell from $75 \%$ in 1957 to $26 \%$ in $1976 .{ }^{\circ}$ But since then the percentage has been on the rise to $88 \%$ in 1987 and is planned to reach $104 \%$ in 1989.

The decreasing central government share of directly collected revenues along with its relatively more slowly decreasing percentage of total expenditure in the 1958-76 period, have clearly made the central government position more difficult in its negotiations with provinces on the transfer of revenues to the centre. The apparently weakened situation of the central government has led to a debate between Western China scholars over the ability of the central government to adopt effective regional policies in the 1960s and 1970s.

Nicolas Lardy has argued that the central government, because of its unweakened system of revenue sharing, has been able to transfer resources from more to less developed regions and has thus at the industrial front carried out its intentions to create greater equality between the provincial units; while Audrey Donnithorne has focused to a greater extent on the central government's reduced revenue percentage and its consequently weakened ability to implement a regional redistribution policy within an intentionally decentralized self-reliance structure, and has claimed that China has a "cellular economy. ${ }^{10}$

Available provincial data on budgets, investments and industrial output value indicate that despite regional decentralization the central government has been able to carry out a regional redistribution policy in the 1960s, the 1970s and until the middle of the 1980s when the reform strategy began to win its foothold on the Chinese economic scene. The background for this is the continued existence of the revenue sharing system. Despite a multitude of changes, the central feature of the budgetary planning process is that there is no functional connection between the size of revenues and expenditures at any level below the national unitary budget. The more rich provinces still finance the greater part of the development of the poorer provinces.

The reasons behind the changing scene in the governmental regional redistribution policy from the middle of the 1980s are multifold: the extra- 
budgetary funds are sharply on the rise, the new revenue sharing system from 1980 favouring especially the more developed coastal provincial units is gradually being carried through, the central government's investment policy in general gives higher priority to some of the more developed coastal provinces, the main part of foreign investment is localized in coastal areas, especially in Guangdong, and finally new investment sources outside the state-sector, i.e. from collective and individual enterprises, are mainly found in richer provinces at the east coast with strong agricultural and light industrial sectors, especially Jiangsu and Zhejiang. The reasons are thus an expression of change in strategy: more coastal than inland orientation.

The new system for sharing revenues between the central and the local government from 1980 was accompanied by greater local financial power to decide over both the revenue and expenditure side of the budget. The provincial units whose total revenues exceed their expenditure share certain types of revenues or all revenues with the central government in fixed percentages, while the provincial units whose revenues are not sufficient to meet their expenditures are granted fixed subsidies by the central government. The revenue sharing percentages and subsidies are fixed for five years. Changes in these rules already were made in 1982.

In the provinces of Guangdong and Fujian a system was introduced in 1980 where the local governments transfer a fixed, unchanged amount to the central government over a five-year period. These two provinces are thus favoured more than the provinces included in the general revenue sharing system. The reason for this favourable position is that the two provinces include the five special economic zones of China. From 1982 onwards the amount transferred from Fujian was changed to a subsidy from the central government.

The most important change in the revenue sharing system took place in 1988, when Shanghai, the biggest contributor of a total of 420 billion yuan in revenues to the central government over the past three decades, introduced a financial contract system. ${ }^{11}$ This is similar to the system practised by Guangdong and Fujian. Instead of keeping a fixed percentage of the total revenues negotiated from year to year, the city will deliver a fixed amount of its revenue intake, i.e. over 10.5 billion yuan annually for the next five years to the central government (compared to over 15 billion yuan in the beginning of the 1980s), and the city will share with the central government half of any additional revenues exceeding 16.5 billion yuan 
by 1991 . This financial decentralization means that Shanghai has to rely more on its local economy and market forces to supply its needs, but also that the central government shall lose revenues and control over capital construction in the biggest metropolis of the country.

Table 3. Provincial Revenues and Expenditures, Distribution over Greater Regions, in percent.

\begin{tabular}{lrrrrrrrrr}
\hline & 1952 & 1957 & 1965 & 1978 & 1980 & 1983 & 1985 & 1986 & 1987 \\
\hline Revenues & & & & & & & & & \\
Coastal & 50.5 & 50.7 & 65.1 & 64.2 & 68.4 & 65.2 & 62.9 & 60.9 & 59.2 \\
Central & 44.7 & 43.5 & 31.2 & 31.6 & 28.5 & 31.8 & 33.6 & 35.1 & 36.6 \\
Border & 4.8 & 5.8 & 3.7 & 4.2 & 3.1 & 3.0 & 3.5 & 4.0 & 4.2 \\
& & & & & & & & & \\
Expenditures & & & & & & & & & \\
Coastal & 49.5 & 45.2 & 44.4 & 44.1 & 44.0 & 43.6 & 45.1 & 45.0 & 45.0 \\
Central & 42.0 & 42.0 & 44.5 & 44.7 & 45.5 & 44.6 & 43.8 & 44.6 & 44.8 \\
Border & 8.5 & 12.8 & 11.1 & 11.2 & 10.5 & 11.8 & 11.1 & 10.4 & 10.2 \\
\hline
\end{tabular}

Note: Figures are based on calculations from provincial budgets.

Table 3 gives a rough picture of provincial distribution of revenues and expenditures, as revenues and expenditures distributed over the greater regions (coastal, central and border) are calculated as a percentage of national total. It can be seen that the contribution of the coastal region to the national total of provincial revenues has been raised from $50.7 \%$ in 1957 to $65.1 \%$ in 1965 , while the coastal region's percentage of national expenditures constantly has been held around $45 \%$ since 1957 . The border area, on the contrary, has had a percentage of national expenditures which since 1957 has been two to four times bigger than its share of revenues. Thus there has been and still is an inverse correlation between the provinces' percentages of total industrial output and their revenue sharing percentages, i.e. the share of the total revenues transferred to the central government, or, if all the revenues are kept, the share of local expenditures that is covered over and above these by central government subsidies. But at the same time as the revenue sharing rates of all important surplus provinces of the coastal region have been falling throughout the 1980s, the number of provinces receiving subsidies has been rising, from 10 in 1978 to about 17 in 1987. This clearly indicates the financial problem of the central government vis-à-vis the provinces. 


\section{Regional Spreading of Investment in Capital Construction}

An effective measure of investment activities in the provinces is the amount of investment in capital construction, as this functionally covers both the economic and social sectors as well as all investments regardless of the source of financing (i.e. both local investments, financed over the provincial budget, direct central government investments in a province, financed over the central government budget, and finally extra-budgetary funds). The investments in capital construction, however, only include investment in stateowned enterprises and not investments in technical transformation, which has become an increasing part of total investment in fixed assets.

Table 4. Investment in Capital Construction, Distribution over Greater Regions, in percent.

\begin{tabular}{lrrrrrrrrrrrr}
\hline & 1952 & 1957 & 1965 & 1978 & 1980 & 1983 & $1983^{1}$ & 1985 & 1986 & 1987 & $1987^{2}$ & $1987^{3}$ \\
\hline Coastal & 52.5 & 37.9 & 35.1 & 43.6 & 47.7 & 49.0 & 43.4 & 51.4 & 53.5 & 55.8 & 55.3 & 57.7 \\
Central & 39.5 & 48.2 & 52.4 & 45.6 & 42.1 & 40.8 & 45.1 & 38.8 & 37.8 & 36.0 & 37.3 & 36.6 \\
Border & 8.0 & 13.9 & 12.5 & 10.8 & 10.2 & 10.2 & 11.5 & 9.8 & 8.7 & 8.2 & 7.4 & 5.7 \\
China & 100 & 100 & 100 & 100 & 100 & 100 & 100 & 100 & 100 & 100 & 100 & 100 \\
\hline
\end{tabular}

${ }^{1}$ Industry only.

2 Total state, i.e. capital construction and technical transformation.

3 Total fixed assets, i.e. state, collective and individual.

Table 4 is an overview of the distribution of investment in capital construction over greater regions, from 1952 to 1987. Alternatively, for 1987, calculations have been also made of distribution of both 1) total state investment, i.e. including capital construction and technical transformation and 2) total fixed assets, i.e. including state, collective and individual investments. For 1983 investment in industry alone has been singled out as a subcategory of total investment in capital construction.

The table shows that the coastal region receives a decreasing share of investment from 1952 to 1965, in reality until the end of the third-line construction in 1971, since then its share is increasing. The opposite is true for the central and border region. But it has to be added that the share of the border region in national population is far less than the region's share in investment, so that per capita investment in this region is particularly high.

In 1983 investment in industry made up $48 \%$ of total in vestment in capital construction. Comparing the shares of the three regions in industry and total investment in capital construction it can be observed, that indus- 
trial investment is much more scattered towards the interior of China (both border and central region) than total investment. This observation can help to explain the continuing spread of industry from coastal to central and border region right up until 1983 (see later section).

If total state investment is considered, the regional distribution is more or less the same as with capital construction alone, but if total fixed assets is considered, i.e. inclusive of collective and individual investment, then the picture is different: the coastal region is winning a higher share, (especially the East region with much light industry, certainly not the heavy industry dominated North East region), and the border region is winning a smaller.

\section{Results of Regional Policy}

It is only for reasons of space that the aggregation of provinces in the traditional greater regions: coastal, central and border has been chosen as basis for the evaluation of regional changes in production 1949-1987 (see Tables 5-7). Many important details will thus be let out, e.g. between the heavy industry dominated North East and the more light industry dominated East region. The development of the backward South West will also disappear as it is part of the central region.

The coastal region consists of 11 provincial units at the east coast belonging to the most developed part of China: Beijing, Tianjin, Hebei, Liaoning, Shanghai, Jiangsu, Zhejiang, Shandong, Fujian, Guangdong and Guangxi. The border region consists of 6 sparsely populated provincial units with many national minorities along the western and northern frontiers: Inner Mongolia, Gansu, Ningxia, Qinghai,Xinjiang and Tibet. The central region of 12 provincial units is situated in between the coastal and border regions (see map). 
Table 5. The Distribution of Agricultural Production and Population in the Greater Regions, in percent.

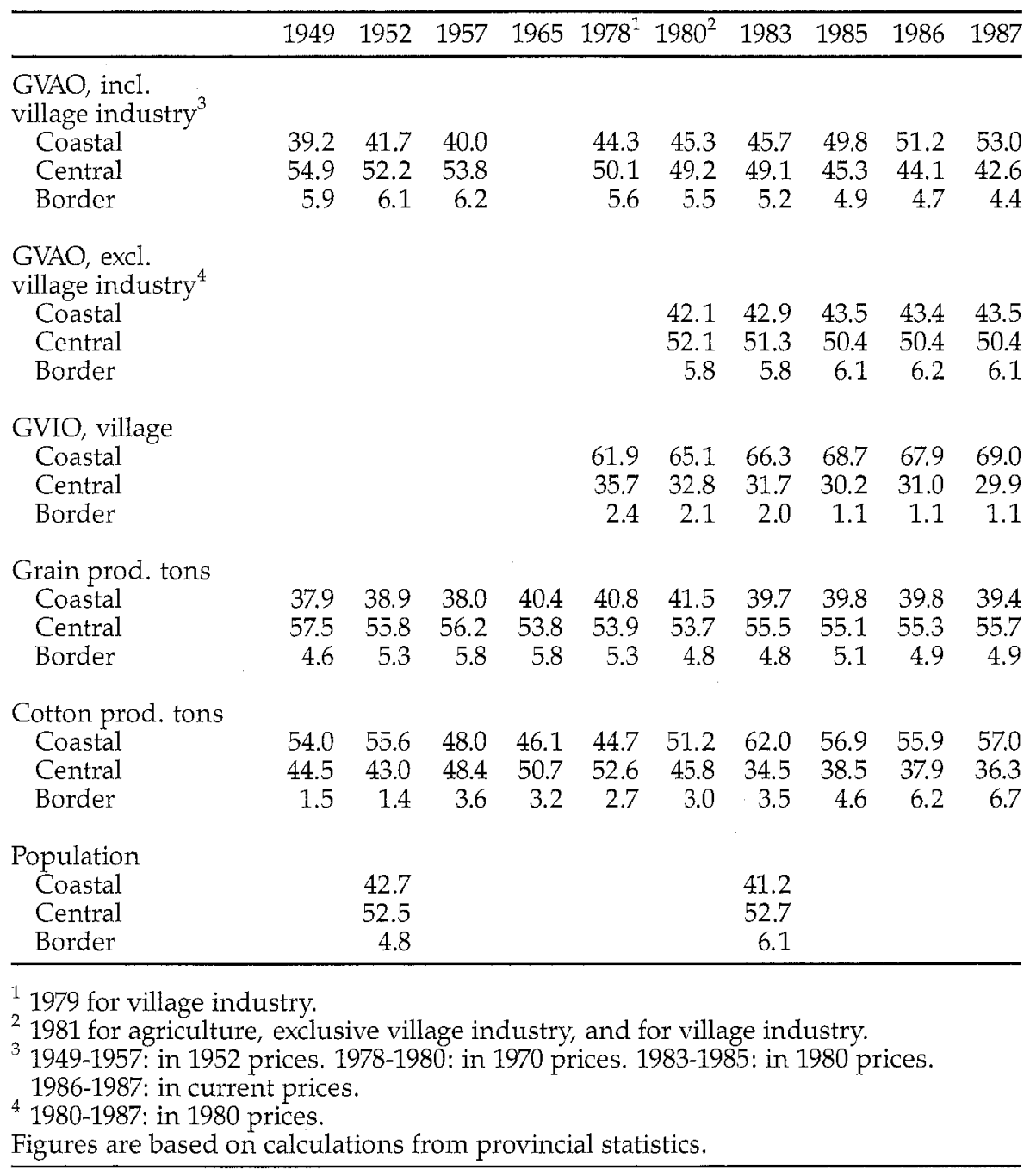


Table 6. The Distribution of Industrial Production over Greater Regions, in percent.

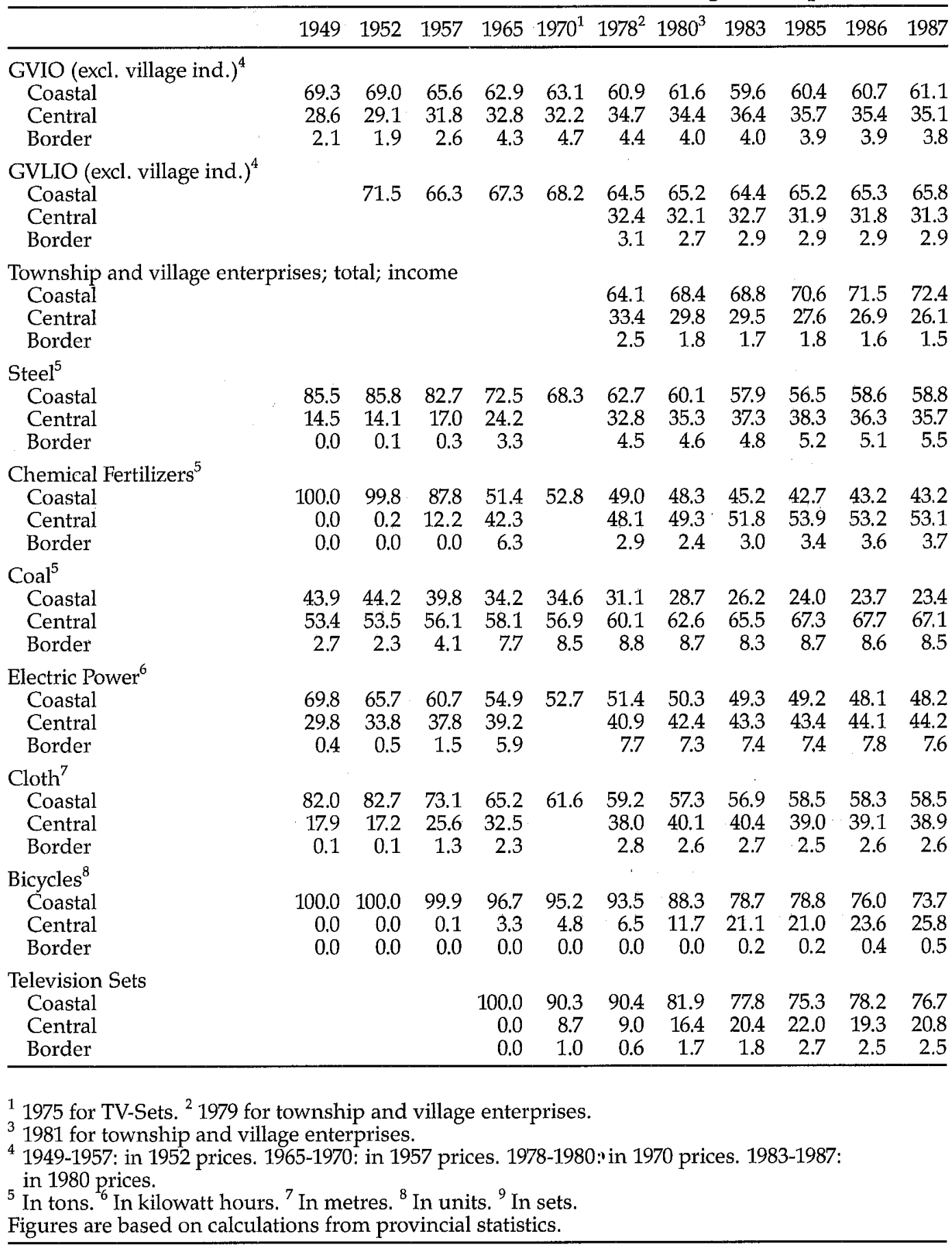


Table 7. Number of Producing Provincial Units.

\begin{tabular}{lrrrrrrrrr} 
& 1949 & 1952 & 1957 & 1965 & 1978 & 1980 & 1983 & 1985 & 1987 \\
\hline Steel & 12 & 15 & 17 & 26 & 28 & 28 & 28 & 28 & 28 \\
Chemical Fertilizers & 2 & 4 & 10 & 27 & 29 & 28 & 28 & 28 & 28 \\
Coal & 26 & 26 & 26 & 27 & 27 & 27 & 27 & 27 & 27 \\
Electricity & 28 & 28 & 29 & 29 & 29 & 29 & 29 & 29 & 29 \\
Cloth & 26 & 26 & 26 & 27 & 28 & 28 & 28 & 28 & 28 \\
Bicycles & 3 & 4 & 5 & 7 & 22 & 23 & 26 & 24 & 24 \\
Television Sets & 0 & 0 & 0 & 3 & 26 & 25 & 26 & 26 & 26 \\
\hline
\end{tabular}

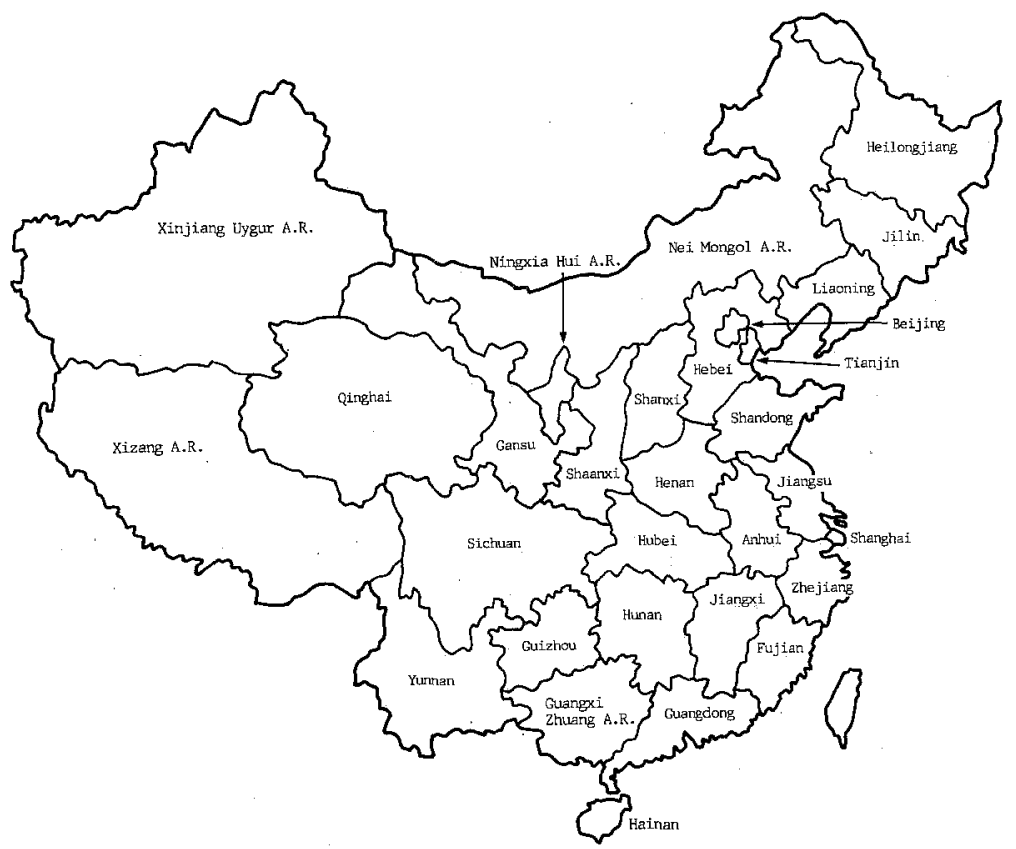

\section{Agriculture}

Concerning agriculture the following indicators has been chosen: agricultural gross output value, both inclusive and exclusive of village industry, as an expression of total output from agriculture, the gross output value of village industry alone, grain production as the dominant basic foodstuff and cotton production as the most important cash crop.

If one looks at agricultural gross output value, village industry included, one can see that there is a gradual concentration towards the developed coastal region: from $39.2 \%$ in 1949 to $53.0 \%$ in 1987 - a devalopment ten- 
dency which however has been briefly interrupted during the First FiveYear Plan of 1953-57. In 1952 the coastal region had a population percentage of $42.7 \%$ as against a rather smaller output percentage of $41.7 \%$; in 1983 the population percentage had been slightly reduced and the gap between population and output had been widened. The opposite tendency is true for the central and border regions.

The concentration tendency in the coastal region is first and foremost due to the rapidly growing concentration of village industry in this region, especially in the East region (Jiangsu and Zhejiang). The coastal region's percentage of village industry rose from $61.9 \%$ in 1979 to $69.0 \%$ in 1987 . If the value of village industry output is deducted from agricultural output value, the distribution of agricultural production over the three greater regions in the 1980s matches on the whole the corresponding distribution of population. Not only the coastal region is gaining slightly, but also the border region.

The calculated data for grain production demonstrate that grain production until 1980 had a regional distribution very similar to the distribution of agricultural output value, since grain still made up a dominant percentage of agricultural gross output value: in 1978, for example, 47.5\%. But from 1980 on the difference grows between the regions' percentage of total output value and grain production (and population), which can be attributed to two development factors: in the first place grain makes up a steadily smaller part of total agricultural output value, among other reasons because of the growth of village industry; and in the second place the tendency for grain production to be concentrated towards the coastal region has been reversed to a spreading tendency, mainly to the benefit of the central region. But the border region is still having difficulty on keeping up.

As for cotton production, the development tendency is the opposite of that of grain production. From 1952 until 1978 there was a fall in the coastal region's, and a corresponding rise in the central region's production percentage; but while the opposite development was weak in the case of grain production, it was striking for cotton production. From 1978 the tendency was reversed: cotton production was dramatically concentrated towards the coastal region at the expense of the central region.

The connection between development of the regional distribution of grain and cotton production is as follows: During the First Five-Year Plan of 1953-57 new cotton producing areas were developed, mainly in the cen- 
tral region, among other places in Hubei. In the 1958-78 period, especially the Cultural Revolution, efforts were made to make the grain deficit provinces on the North Chinese Plain in the coastal region - Shandong and Hebei - self-sufficient in grain, which drastically affected cotton production. And finally, in the period since 1978 there has been intense specialization within cotton production, first and foremost moving back towards Shandong and Hebei. But at the same time efforts have been made not to neglect grain production in these provinces. Also the border region is gaining percentages because of building new cotton areas in Xinjiang.

The case of agricultural production can on the whole be summed up by saying that since 1949 there has been a weak, gradual concentration towards the coastal region (apart from the 1953-57 period). The concentration tendency since 1978 is thus not a new, but a continuing phenomenon. This emphasizes the fact that the Maoist self-reliance strategy in the case of collectivized agricultural production involves a tendency to aggravate the regional differences by favouring the best-equipped regions. The centralized redistribution policy is only a realizable strategy within the stateowned sector. Since 1978 the concentration towards the coastal provinces has been particularly strong in the case of cash crops like cotton and the flourishing village industry enterprises, which take advantage of the proximity of the big cities. But grain, as the most important basic foodstuff, has been exempt from this specialization tendency. All provincial units, in theory, are to aim at self-suffiency. But some provinces falling behind, all located in the coastal region, are being accused of neglecting grain production for more lucrative cash crops: Guangdong, Guangxi and Fujian.

\section{Industry}

The evaluation of regional development in industrial production is dealt with on the basis of the following indicators: industrial gross output value as an expression of total industrial production, the light industrial sector alone, steel production as the most important semimanufactures industry, chemical fertilizers as industry's most important input into the agricultural sector, coal and electric power as the most important fuel products, the production of cloth as the most important everyday consumer commodity, production of bicycles and television sets, two important consumer durables and income from the rural enterprises, which are only partly included in industrial gross output value - see Table 6. 
As far as the total industrial output is concerned there has been a continuing shift of production percentages from the coastal region towards the inland region, from 1949 right up until 1983. The production percentage of the coastal region was thus reduced from $69.3 \%$ in 1949 to $59.6 \%$ in 1983 . The central region had its maximum percentage in 1983 (36.4\%), but the border region, as early as 1970 (4.7\%). There is, however, still an industrial concentration in the coastal region, as this in 1983 had a population percentage of $41: 2 \%$. The deepening of existing regional differences within industry did not, then, restart until after 1983, i.e. in connection with carrying through of reform strategy - and only slightly.

The degree of industrial concentration in the coastal region was reduced for both heavy and light industry, but light industry is more concentrated towards the coastal region than heavy industry, and the degree of concentration of light industry was reduced less than that of heavy industry. After 1983 the border region retained its percentage of light industry output at $2.9 \%$, i.e. only the central region became a loser.

The geographical localization of steel production has been subject to a constant shift since 1952 from the coastal region towards the central and border region. Only after 1985 the coastal region is regaining percentages, but the border region is gaining still.

In 1949 the production of chemical fertilizers was concentrated in the coastal region alone, but the geographical localization has since then favoured the central and border regions. After 1985 the coastal region is gaining small percentages, but this is also the case with the border region. The regional localization corresponds, apart from the border region, on the whole with the regional distribution of population - and grain production. With the starting up of the imported nitrogen fertilizer plants in Xinjiang and Ningxia the border region's percentage will continue to rise.

Coal was the only one of the products included that was produced more in the central than in the coastal region in 1949. Since 1949, and escpecially since 1978 the production of coal has to an even greater extent been concentrated towards the central region (especially Shanxi) and the border region. The localization of the coalmines has thus been adapted more and more to the sites of coal deposits. The localization of coal production also underscores the coastal region's weak energy resource basis.

The regional distribution of electric power in 1949 in the coastal and central regions corresponded very precisely with the distribution of total industrial output in these regions. After 1949, and right up until 1987, the 
central and border regions' production percentages grew steadily. In 1987, power production was considerably more even distributed regionally than the corresponding regional distribution of industrial output. This emphasizes the shortage of energy supplies in the coastal region, making for poor utilization of industrial capacity.

Light industry production was and still is, as far as most products are concerned, considerably more concentrated towards the coastal region than heavy industry in general. The coastal region's production percentage for cloth in 1949 was as high as $82 \%$. In 1987, however, its percentage of $58.5 \%$ was smaller than its percentage of total industrial output value $(61.1 \%)$. But the coastal region began to regain percentages already after 1983.

In 1949 the production of bicycles was concentrated in three assembly factories in the coastal region. The production of television sets, which started on a small scale in 1958, was up to 1965 entirely concentrated in the coastal region. Since 1978 there has been a considerable spread of the strongly coast-concentrated production of both to the central region, and the beginnings of a spread to the border region, especially for television sets. This spread is continuing after 1985 for bicycles, but not for television sets.

As to the total income of xiang and village enterprises the production percentage of the coastal region was the only one of the types of production selected to concentrate already from 1978. The rural enterprises are more concentrated towards the developed provincial units of the coastal region than industrial production as such, especially towards the East region (Jiangsu and Zhejiang).

The case of industry in different strategic periods can be summed up as follows. The priority given to heavy industry in 1953-78 did not only benefit the traditional heavy industry centres in the North East, but also new centres in the interior of China - i.e. provincial units in the central region: Shanxi, Henan, Hubei, Hunan, Sichuan, Guizhou, Yunnan and Shaanxi as well as in the border region: Inner Mongolia, Gansu, Ningxia, Qinghai, Xinjiang and Tibet. In 1978 the heavy industry production percentage was particularly high, i.e. over $65 \%$, in Heilongjiang and Liaoning in North East, Shanxi in North, Guizhou and Tibet in South West and Gansu, Ningxia and Qinghai in North West. Of the provincial units mentioned that were dominated by heavy industry, all except the northeastern provinces, managed to increase their production percentages of total gross 
output value between 1952 and 1978.

The impact of the readjustment strategy 1979-83 meant higher priorities for light industry at the expense of heavy industry, and thus a new situation for the provincial units dominated by heavy industry. Those provincial units that also had relatively well developed light industry improved their production percentage of national light industry between 1978 and 1983 (Heilongjiang, Liaoning, Hubei, Hunan, Sichuan and Yunnan): A few provincial units increased their production percentage of national heavy industry, first and foremost because of high priority given to the development of local energy resources (Shanxi, Inner Mongolia, Henan, Hubei, Sichuan, Guizhou, Yunnan and Xinjiang).

But a few of the provincial units dominated by heavy industry were in a weak position with the shift in strategy after 1978 - the poorly developed provincial units in the North West, Gansu, Ningxia, and Qinghai, along with Tibet in South West. The heavy industry sector is dominated by relatively large state owned-factories, often producing at a loss. The bulk of these factories are concentrated in a few dominant cities, with poor linkages to the rest of the economy. In the 1979-83 period these four provincial units had the lowest growth rate of all provinces. These four provincial units have plentiful energy resources, especially hydropower and are therefore a potential surplus area for electric power. A potentially more succes ful development strategy in these provincial units is also latent in the development of local industry, among other places in national minority areas, based on craft-orientated consumer goods industry. Such a restructuring would take longer time than in other provinces.

During the years of reform after 1983 the readjustment of the industrial structure stabilized, as heavy industry had the same percentage of national industrial output, i.e. about $50 \%$. It is interesting that, for the bulk of the industrially developed provinces, the heavy industry percentage either stayed at the same level as in 1983 or slightly increased, while the readjustment of the industrial structure towards more light industry continued for most of the undeveloped provinces and those dominated by heavy industry, for example in Inner Mongolia in North, Gansu and Ningxia in North West and Guizhou in South West. The ever improving light industry situation in these weakly developed provinces may in the rather longer term help to improve the basis for the provinces' own accumulation, and thus make for a higher rate of growth. If the growth rates are compared in the 1979-83 and 1984-87 periods, it can be observed that there is 
a striking improvement for all four provincial units. The restructuring is thus already having its effect.

As can be seen from Table 7 regional specialization is almost non existent in the Chinese economy. In 1983 the industrial products included in this paper were produced in at least 26 of the 29 provincial units. This industrial spread, unique in the international context, has happened despite the clear economic advantages connected with regional specialization and commodity exchange. The Chinese economic planning system has favoured local self-reliance at the provincial level, strongly backed by centralized redistribution, even after 1978, when regional specialization was on the agenda. Thus the number of provinces, for example, that produce bicycles has risen from 22 in 1978 to 26 in 1983. The advantages of regional specialization have been debated theoretically, but it was not until the 1980 s that the number of factories in certain commodity categories was adjusted, and the reduction of factories has generally taken place very slowly and to a limited extent. In the course of 1985, for example, the number of bicycle producing provinces was reduced from 26 to 24 .

In the near future reforms will slow down. Calling the natural allies of the reform strategy, i.e. leaders of the big cities, to the center, as happened after the events in Beijing in early June in the case of Jiang Zemin from Shanghai and Li Ruihuan from Tianjin, will weaken the reform faction within the party leadership. Therefore, China's regional structure will not see any big changes in the next years to come.

Kjeld A. Larsen is a Senior Research Fellow at the Center for East and Southeast Asian Studies, University of Copenhagen, working on a research grant from the Danish Social Science Research Council. 


\section{NOTES:}

1 An outline of the main elements of the four abovementioned development strategies as a frame of reference for regional policy will not be dealt with in this article, but wil appear in my forthcoming book The Regional Policy of the People's Republic of China 1949- 1985 Aims, Strategies and Results (Journal of Contemporary Asia Publishers).

2 In Western language literature this conflict was first addressed by Franz Schurmann in his Ideology and Organization in Communist China (Berkeley: University of California Press, 1970), pp. 188-194. A recent excellent discussion of the conflict appears in Jonathan Unger, «The Struggle to Dictate China's Administration: The Conflict of Branches vs. Areas vs. Reform, "The Australian Journal of Chinese Affairs No. 18 (July 1987), pp. 15-46.

3 Chen Jiyuan, "Regional Economic Structure, " in China Report, Economic Affairs, JPRS-CEA-84-064 (August 3, 1984).

4 Ma Hong, New Strategy for China's Economy (Beijing: New World Press, 1983) Chapter IV.

5 An example of an article on economic zones is Sun Xiaoliang, Ji Zheng, Shi Huimin and Yang Yurun, "An Initial Study of the Way to Form Economic Zones with Cities as the Centers," China Report, Economic Affairs JPRSCEA-84-012 (February 2, 1984).

6 The Sixth Five-Year Plan of the People's Republic of China for Economic and Social Development 1981-85 (Beijing: Foreign Languages Press, 1984), Part Three.

7 "The Seventh Five-Year Plan of the People's Republic of China for Economic and Social Development (1986-90), Ex- cerpts, "Beijing Review, 1986, No. 17, Section Three.

8 See State Statistical Yearbook1988, p. 682. Financial figures for 1988 and planned figures for 1989 in this article are from Wang Bingqian, »Report on the Implementation of the State Budget for 1988 and on the Draft State Budget for 1989, " Beijing Review, 1989, No 18.

9 See State Statistical Yearbook 1988, p. 665.

10 Important contributions in the ongoing debate between Nicolas Lardy and Audrey Donnithorne are: Donnithorne, sThe Budget and the Plan in China: Central-Local Economic Relations, "Contemporary China Papers, No. 3, 1972; Donnithorne, "China's Cellular Economy: Some Economic Trends Since the Cultural Revolution, "The China Quarterly (October-December 1972), No. 52, pp.605-619; Lardy, "Centralization and Decentralization in China's Fiscal Management, "The China Quarterly (March 1975), No. 61, pp. 25-60; Donnithorne, "Centralization and Decentralization in China's Fiscal Management, Comment, "The China Quarterly (June 1976) No. 66., pp. 32840; Lardy, "Centralization and Decentralization in China's Fiscal Management, Reply, "The China Quarterly (June 1976), No. 66, pp. 340-54; Lardy, Economic Growth and Distribution in China (Cambridge: Cambridge University Press, 1978); Donnithorne, „CentreProvincial Economic Relations in China, "Contemporary China Paper, No. 16, 1981; Donnithorne, "Fiscal Relations, "The China Business Review (November-December 1983),pp. 25-27.

11 Xinhua News, February 10, 1988 and Xinhua News, April 21, 1988. 